\title{
Measuring our work: Scenarios to value productivity in health care
}

\author{
Hans-Jakob Steiger
}

Received: 23 June 2008 / Accepted: 5 August 2008 /Published online: 15 May 2009

(C) Springer-Verlag 2009

Keywords Productivity $\cdot$ Health care

Traditionally, the services of physicians were appreciated according to market value depending on the severity of the disease treated and also depending on the public image of the profession. Productivity and efficiency were of no general interest; time management was up to the individual practitioner or hospital staff. With the working hours initiatives in Europe and the US, the situation has changed fundamentally.

With the definition of maximum weekly working hours, the time spent in the hospital began to be considered as the work. It is certainly not far-fetched to say that the days are numbered in which the physician's performance is assessed based on the hours spent at work. Efficiency and productivity considerations are likely to take over sooner rather than later. The purpose of this study was to provide some concepts on productivity management and to indicate possible directions in which assessment of our work might go.

\section{Current developments}

One method of accounting for the costs associated with providing a service is to use a resource-based relative value scale (RBRVS) to index the procedures on a common basis $[3,7]$. In the USA, Medicare and most HMOs use such a system of relative value units (RVU) to compare the procedures. Typical examples from Europe are the Swiss

\section{H.-J. Steiger $(\varangle)$}

Department of Neurosurgery, Heinrich Heine University,

Moorenstraße 5, Geb. 13.71,

Düsseldorf 40225, Germany

e-mail: steiger@uni-duesseldorf.de
TARMED scale or the German DRG scales. In the development of the RBRVS, the physician's work, including the time, mental effort, technical skill, judgment, stress and an amortization of the physician's education, the practice expense and the malpractice expense are factored into the result. The RBRVS does not include adjustments for outcomes, quality of service, severity or demand. The actual fee is calculated from the RVUs after geographic adjustment and also possible adjustment to achieve, for example, budget neutrality. A group practice or hospital should calculate RVUs for each provider in the group, including physicians, therapists and other allied health providers. Data then can be generated regarding productivity by individual or group. RBRVS cost accounting can also be used to calculate the profitability of the practice's allied providers. For example, a practice employs a physical therapist who is paid a salary and provided with an office and treatment space. An analysis of the practice's revenue and expenses in relation to the RVUs produced by the therapist will show whether the income produced by this allied provider covers the expenses.

It can be difficult to use this system in a group practice or hospital to assess the productivity of the individual team members if there are interdependences between the different providers. Let's assume a group practice consisting of a general practitioner (GP), a cardiologist and a gastroenterologist. The specialists generate more RVUs than the GP, but they depend on the referrals by the GP.

Despite some concerns, RBRVS cost-accounting systems are increasingly adopted by managed health-care systems. To be effective, the RBRVS cost-accounting system must be communicated to physicians in a clear and understandable manner. Periodic financial reports for each physician are recommended to sharpen the physicians' consciousness of their productivity. 


\section{Worker productivity measurement \\ in the industries-what we should expect also in health care}

In most industries the quantity of labor input in production is measured by hours worked and its price by average compensation per hour [5]. Although a worker's contribution to the production process is usually paid on the basis of his/her "raw" labor or physical presence, $1 \mathrm{~h}$ worked by one person does not necessarily constitute the same amount of labor as $1 \mathrm{~h}$ worked by another person. There may be differences in skills, education, motivation, health and experience that lead to large variations. A differentiation of labor input by type of skills is particularly desirable if one wants to capture the effects of a changing quality of labor on the growth of output and productivity. Explicit differentiation is, however, data- and research-intensive. Jorgenson et al. [4] have used as many as five characteristics (age, education, class of workers, occupation and gender) to cross-classify labor input by detailed industry. Another possibility is to use a small number of differentiating characteristics but to choose them so as to minimize the correlation between them. This is the approach adopted for example by the US Bureau of Labor Statistics: hours worked are cross-classified only by educational attainment and work experience and industry $[1,8]$.

Regardless of whether there is one or a number of differentiating traits, hours of highly skilled persons and hours worked of unskilled persons cannot simply be added to obtain an aggregate measure of labor inputthey have to be weighted by their respective relative productivity to account for differences in skills. Theoretically, labor of a certain type will be hired up to the point where the cost of an additional hour of labor is just equal to the additional revenue that using this labor generates. This equality implies that, for a measure of total labor input, the individual labor inputs of different quality can be weighted with the respective relative wage rate, or more specifically, with the share that each type of labor occupies in total revenues.

Even when only a simple trait such as occupation is chosen to differentiate labor input, information requirements are severe. Implicit differentiation can provide a substitute. Implicit differentiation arises when labor input (simple hours worked) is measured by detailed industry without, however, distinguishing between different types of labor within each industry. When hours worked by industry is aggregated to the economy-wide level and compared to the industry's share in total labor compensation, industries that pay above-average wages and below-average wages can be identified. Assuming that above-average wages reflect above-average skills of the workforce, some of the quality aspect of labor input is taken into account (Table 1).

\section{Assessment of individual productivity-also to be expected in health care}

Work measurement involves the use of labor standards to measure and control the time required to perform a particular task or group of tasks [9]. Most often labor standards are developed and applied in manufacturing operations; however, labor standards can be used in estimating and managing the cost of a vast variety of activities including business accounting, clerical administration and janitorial services.

Labor standards are commonly grouped into two types. Engineered standards are developed using recognized

Table 1 Excerpt from US Bureau of Labor Statistics: Percent change in output per hour, output, hours, compensation and unit labor costs, 20052006 [6]

Percent change, 2005-2006

\begin{tabular}{|c|c|c|c|c|c|c|c|}
\hline \multirow[t]{2}{*}{ NAICS } & \multirow[t]{3}{*}{ Industry } & \multicolumn{6}{|l|}{2006} \\
\hline & & Employment & Output & Total & Total & Total & Unit labor \\
\hline Code* & & (Thousands) & Per hour & Output & Hours & Compensation & Costs \\
\hline \multicolumn{8}{|c|}{ Manufacturing } \\
\hline 311 & Food & 1,479 & -1.7 & 1.1 & 2.9 & 1.8 & 0.7 \\
\hline 312 & Beverages and tobacco products & 194 & -6.4 & -1.9 & 4.9 & 2.8 & 4.8 \\
\hline 313 & Textile mills & 195 & -1.5 & -11.2 & -9.8 & -7.3 & 4.4 \\
\hline 314 & Textile product mills & 161 & -5.4 & -8.5 & -3.2 & -3.6 & 5.3 \\
\hline 315 & Apparel & 238 & 2.8 & -3.1 & -5.7 & -4.0 & -0.9 \\
\hline 316 & Leather and allied products & 37 & 7.1 & -2.6 & -9.1 & -1.7 & 1.0 \\
\hline
\end{tabular}

*North American Industry Classification System 
principles of industrial engineering and work measurement. The standards developed define the time necessary for a qualified worker, working at a pace ordinarily used, under capable supervision, and experiencing normal fatigue and delays, to do a defined amount of work of specified quality when following the prescribed method. Non-engineered standards are developed using the best information available without performing the detailed analysis required to develop engineered standards. Historical labor costs are commonly used to calculate the hours that have been required to complete a task rather than the hours that should be required.

Labor standards provide information on what it should cost to complete an operation or series of operations in product production. Instead of applying pressure to improve in all areas, managers can use this information to identify areas requiring particular management emphasis. The acquisition team can use that same information to identify inefficient operations for close scrutiny during contract negotiations.

An engineered labor standard is composed of three elements: leveled time; a personal, fatigue and delay (PF\&D) allowance, and possibly special allowances. Leveled time is the time that a worker of average skill, making an average effort, under average conditions, would take to complete the required task. There are a variety of techniques used in leveled time development, but the three used most commonly are: (1) time study, (2) calculation based on predetermined leveled times established for basic body motions, such as reach, move, turn, grasp, position, release or groups of motions and (3) work sampling based on a large number of random, rather than continuous observations. Estimates are based the proportion of time spent by one or more persons on a given activity. This is useful for jobs with irregular components that vary in the amount of time per unit of output.

After the leveled time is developed, estimators must consider a personal, fatigue, and delay (PF\&D) allowance. Each allowance should be identified and quantified. A personal allowance considers time for a worker to take care of personal needs, such as trips to the rest room and drinking fountain. A fatigue allowance considers the time required to recuperate from fatigue. A delay allowance covers unavoidable, predictable and unpredictable delays that cannot be prevented by the employee. Total PF\&D allowances typically amount to 15 percent. However, allowances may be higher or lower depending on the nature of the work and related working conditions. For example, strenuous work in an extremely hot environment would typically merit a higher PF\&D allowance than light labor performed in an air conditioned room.

Labor standards represent goals for efficient operation. Tasks are rarely completed in the allowed standard time.
Work measurement systems commonly use realization or efficiency factors to evaluate how the actual time required to complete a task compares with the standard time for that task. Analysts can then use these measures to identify tasks that require special analysis to identify and correct inefficient operations. An efficiency factor can be calculated to demonstrate efficiency against the standard, e.g., if a task takes twice as long as the standard the efficiency factor would be calculated as $50 \%$.

Modern electronic tools can be used to calculate efficiency immediately and give a feedback to the workers. Goomas reported a study of immediate performance feedback and self-monitoring delivered to employees of an auto parts after-market distribution center [2]. Following installation of immediate performance feedback on wireless vehicle-mounted computers, order picking performance improved by three cases per hour per person. The intervention package included the depiction of actual performance and of goal times according to a newly developed engineered labor standard.

\section{Concluding remarks}

RBRVS accounting is already implemented to measure physician's work. The impact of measuring our work based on a purely economic taxonomy is serious and has completely changed our value system away from the old Hippocratic ideals. The other mentioned scenarios taken from the industry are not yet consequently implemented in health care, but the current process-oriented tools of quality management obviously open the doors to use the same tools also for efficiency management. Process control in the industries has been used for more than a century, and the introduction of scientific process management is credited to Frederick W. Taylor, who was born in 1856 in Boston [6]. As a child, he is said to have been enamoured of "rule structures as a means of social control." From 1878-1889, he was employed at Midvale Steel, where he worked his way up to shop superintendent. It was during this period that he developed his theory of "scientific management." Taylor claimed to have conducted experiments in varying conditions. For example, if the job was shoveling, a larger shovel blade could move more material in a single stroke, but it would also tire the men more. Taylor gave the men shovels with smaller and smaller blades each day until the amount shoveled in a day began to fall. Thus, he determined the most efficient size of the tool for each task. Through studies such as these, Taylor was able to reduce the number of shovelers at the Bethlehem Steel Works, where he was then employed, from 500 to 140. Today Taylor's name is generally associated with the "stopwatch method" to measure and optimize work processes. 
The hype of process control in the industries has been over for some decades because it was realized that overemphasis of process control may reduce motivation. Target-defined performance measures and corresponding financial incentives have partially replaced process-oriented control. In the intellectual professions, however, a revival of Taylorian process control is seen today. Today's electronic possibilities that allow for exact tracking of many activities are certainly an important factor for the resurrection of these old concepts.

\section{References}

1. Deutsches Statistisches Bundesamt (2997) Produktivität und Lohnkosten. http://www.destatis.de

2. Goomas D (2007) Electronic performance self-monitoring and engineered labor standards for "man-up" drivers in a distribution center. J Bus Psychol 21:541-558

3. Hollingsworth B, Dawson PJ, Maniadakis N (1999) Efficiency measurement in health care: a review on non-parametric methods and applications. Health Care Manag Sci 2:161-172

4. Jorgenson D, Gollop F, Fraumeni B (1987) Productivity and US economic growth. Harvard University Press, Mass

5. OECD (2001) Productivity measurement. http://www.oecd.org/ dataoecd/59/29/2352458.pdf

6. Pomerantz LE ( 2000) Changes in management theory during the twentieth century. http://www.teachspace.org/personal/index.html

7. Shackelford, JL ( 1999) Measuring productivity using RBRVS cost. Healthcare Financial Management, January 1 1999, http://www. allbusiness.com/healthcare-financial-management/19990101/ 2990168-1.html

8. U.S. Department of Labor, Bureau of Labor Statistics (2006) Overview of BLS Productivity Statistics. http://www.bls.gov/bls/ productivity.htm
9. US Department of Defense (2005) Defense Procurement and Acquisition Policy - Contract Pricing Reference Guides. http:// www.acq.osd.mil/dpap/contractpricing/vol2chap8.htm

\section{Comment}

How well this vision will be true, especially in neurosurgery, is not clear - there is a long tradition of quality control, outcome analyses of procedures and well-functioning quality assurance systems in many European university departments beginning already with yearlong budget neutrality (Pickard et al., 1991). The neurosurgical procedures are mostly centralized and then easier to evaluate, but still the problems are numerous; teaching, research and education at all levels have to be considered. The basic question of what really is expensive and what is cheap in the total care of an individual patient may be difficult; well-planned consensus meetings could be one step in the right direction concerning what a planned regular re-evaluation means as well.

I have lived in the time of unlimited working hours and do not hope for that kind of time for the next generations. Neurosurgeons in leading positions should be able to build a fair new working system where patients are treated at the right time, with well-paid on-call hours for extra work to the staff and with enough rest for compensation. Work should be divided well with motivated, educated surgeons who get a fair and continuous feedback from their patients, colleagues, other health professionals and administrative coworkers. This basic difference in motivation makes the hospital such a special production facility, which at its best is self controlling.

\section{References}

1) Pickard JD, Bailey S, Sanderson H, Rees M, Garfield JS: Steps toward cost-benefit analyses of regional neurosurgical care.BMJ. 1990 Sep 29:301(6753);(629-35)
M. Vapalahti Kuopio University Hospital, Finland 